\title{
Erratum to: Which environmental factors trigger the dominance of phytoplankton species across a moisture gradient of shallow lakes?
}

\author{
Irina Izaguirre • María Laura Sánchez • M. Romina Schiaffino • Inés O'Farrell • \\ Paula Huber • Nora Ferrer · Josefina Zunino • Leonardo Lagomarsino • Miguel Mancini
}

Published online: 23 August 2016

(C) Springer International Publishing Switzerland 2016

\section{Erratum to: Hydrobiologia (2015) 752:47-64 DOI 10.1007/s10750-014-2007-1}

Due to an unfortunate mistake, an error occurred in the conversion of the algal biovolumes to algal biomass. The correct values of phytoplankton biomass are one order of magnitude lower than those published. This error occurs on page 53 and in Fig. 4. The text on page 53 should have read:

“...total algal biomass (3.4-128.5 $\mathrm{mg} \mathrm{l}^{-1}$ ). The saline lake SA also showed rather low algal biomass (3.6-17.6 $\left.\mathrm{mg} \mathrm{l}^{-1}\right) \ldots$..; “...total phytoplankton biomass varied from 4.5 to $1781.6 \mathrm{mg}^{-1} \ldots$..
The online version of the original article can be found under doi:10.1007/s10750-014-2007-1.

I. Izaguirre $(\bowtie) \cdot$ M. L. Sánchez · M. R. Schiaffino ·

I. O'Farrell

Departamento de Ecología, Genética y Evolución, IEGEBA (UBA - CONICET), Facultad de Ciencias Exactas y Naturales, Universidad de Buenos Aires, Buenos Aires, Argentina

e-mail: iri@ege.fcen.uba.ar

P. Huber · L. Lagomarsino

Instituto de Investigaciones Biotecnológicas, Instituto Tecnológico de Chascomús (IIB-INTECH), CONICET, Chasmomús, Argentina
N. Ferrer · J. Zunino

Departamento de Biología, Bioquímica y Farmacia,

Universidad Nacional del Sur, Bahía Blanca, Argentina

M. Mancini

Ecología y Acuicultura, Facultad de Agronomía y Veterinaria, Universidad Nacional de Río Cuarto, Río Cuarto, Córdoba, Argentina 